\section{ELECTRIC STRENGTH OF VARNISH FILMS}

TN a paper entitled "Intrinsic Electric Strength and 1 Conductivity of Varnish Films and their Variation with Temperature" (J. Inst. Elec. Eng., 89, Pt. 1, No. 23; November 1942), A. Morris Thomas and Miss M. V. Griffith discuss recent advances in the theory of the intrinsic electric strength of solids, and describe methods for the preparation and testing of samples of baking insulating varnishes and shellacvarnish films for the determination of their intrinsic electric strength. The varnishes tested were a clear baking oil insulating varnish, a black baking bituminous insulating varnish, a synthetic-resin insulating bakelite varnish, and a pure de-waxed lemon shellac varnish.

The results of the tests made on a thickness range of $0.02-0.1 \mathrm{~mm}$., and a temperature range down to $-196^{\circ} \mathrm{C}$, are reported. The investigation also includes conductivity measurements, effect of different ambient conditions (immersion media and applied pressure), time/voltage tests, and the effect of centrifuging and filtering and comparison tests on varnish-impregnated paper films, which were made to establish the validity of the method of test and to assist interpretation of the results.

The large and continuous increase of intrinsic electric strength with decrease of temperature down to $-196^{\circ} \mathrm{C}$. which is found disposes of the assumption hitherto made by some investigators that this quantity is independent of temperature. Consideration of the results in relation to the recent theory proposed by Frohlich to account for a temperaturedependence of the character obtained indicates that this theory in its present form is not applicable, but an alternative explanation is suggested.

As the results of the research, the investigators reach the following conclusions. The intrinsic electric strength of varnish films is probably independent of thickness from $0.02 \mathrm{~mm}$. to about $0.1 \mathrm{~mm}$. at all temperatures, except that clear varnish films show a small decrease with the thicker samples at $90^{\circ} \mathrm{C}$., and at low temperatures $0.04 \mathrm{~mm}$. was the maximum thickness tested. The values for all four types of varmish investigated at $-196^{\circ} \mathrm{C}$. lie between 8,000 and $9,000 \mathrm{kv} . / \mathrm{cm}$. and decrease approximately linearly with increase of temperature up to $0^{\circ} \mathrm{C}$., the exception being clear varnish. Above about $0^{\circ} \mathrm{C}$. the decrease continues at a slower rate up to $60^{\circ} \mathrm{C}$., and the values then tend to increase slightly up to $90^{\circ} \mathrm{C}$., except that shellac gives a sharp fall. As the rates of decrease with increase of temperature differ, the values diverge, so that at $60^{\circ} \mathrm{C}$. the maximum values are approximately $4,900,3,300,2,600$ and $2,200 \mathrm{kv}$. $/ \mathrm{cm}$. for the bakelite, shellac, black and clear varnish films respectively. The intrinsic electric strength of the bakelite varnish films is independent of time of application of voltage within the experimental range, but the other varnishes show decreases in maintained-voltage tests, which, however, may be a consequence of local defects due to inclusions or lack of film uniformity.

Relatively large inclusions of a dielectric such as cellulose in the form of paper are found not to affect appreciably the intrinsic electric strength of varnish films. The variation of the conductivity of varnish films with temperature is apparently of a complex nature and is not of a type which enables definite conclusions to be drawn with regard to the mechanism, although the results are qualitatively understandable if it be supposed that ionic conduction occurs at high, and electronic conduction at low, temperatures. The results may be considered in relation to the theory of the breakdown of organic solids recently developed by Frohlich. If electronic conduction only is assumed, then the intrinsic electric strength of a pure paraffin consisting of long-chain crystals should increase with increase of temperature, but the introduction of polar groups into the molecules may outweigh this effect and cause a decrease. For this type of variation to occur, it is necessary that the temperature be sufficiently high to enable certain of the molecular groups to rotate, and such an effect may be recognized by an increase of dielectric constant.

The investigations of phenolformaldehyde varnish films by Hartshorn, Megson and Rushton show that an increase of dielectric constant due to dipole rotation in substances of this type does not occur until a temperature of $20^{\circ} \mathrm{C}$. is attained; the dielectric constant then rises from about 3 to a value of 7.6 at $80^{\circ} \mathrm{C}$. This region corresponds to that over which the intrinsic electric strength of the varnish films remains approximately constant, so that the theory in its present form is inadequate to explain the results. There remains a possibility that the change of the course of the temperature variation which occurs roughly at normal temperature may be related to the change in the conduction mechanism at about the same temperature. Reference is made to the agreement of the results with those obtained on amorphous glass. It is suggested that, with materials of the type which have a colloidal structure, a falling intrinsic electric strength/temperature characteristic may be explained by the relative ease of electronic or ionic movement along internal surfaces.

The paper is based upon report Ref. $L / T 120$ of the British Electrical and Allied Industries Research Association.

\section{INTUITIVE KNOWLEDGE}

TN a paper on intuitive knowledge in the issue of Mind of October, 1942, Prof. R. I. Aaron considers the present position of the time-honoured doctrine that there are certain propositions which the human mind can know without any shadow of doubt or possibility of error. This doctrine, a legacy in European thought of the philosopher-scientist Descartes, who took the deductive reasoning in geometry as the pattern of scientific thinking and the self-evident axioms of Euclidean geometry as the foundations thereof, has come to seem less compelling now that those axioms are no longer regarded as self-evident by any educated person.

The author agrees, however, that to conclude from this that the whole notion of intuitive knowledge must be discarded would be precipitate. Those who do so, assert that any so-called piece of intuitive knowledge is either merely a statement as to how certain linguistic forms are used (for example, when I know that 'no fishes have hair' necessitates that 'no creatures with hair are fishes', I am not really knowing anything except the rule by which one English sentence can be transformed into another); or, if such knowledge goes beyond words to the real world, it can never be absolutely certain (for example, when I know that my hand is before me 
moving my pen across the page, there is some possibility, however small, of error). This latter conclusion is based on the assumption that, as all state. ments about the empirical are based on evidence, there may at any given point be more evidence forthcoming which would shake the certainty of the statement.

In defence of intuitive knowledge the author maintains that there are propositions which depend on evidence but yet are absolutely certain because there is such a thing as conclusive evidence. For example, I do know my hand is now moving my pen across the page. This is an example of undoubted knowledge. This has been said before, of course, but it was worth while saying again in face of modern tendencies to dissolve away knowledge into mere guessing about a universe hidden behind the veil of sensation.

\section{PERICARDIUM AND PERICARDIAL GLAND IN THE LAMELLIBRANCHIA}

THE most recent number of the Proceedings of the Malacological Society of London (25, Pt. 2) is entirely occupied by an important paper by Dr. Kathleen M. White on "The Pericardial Cavity and Pericardial Gland of the Lamellibranchia". Present and future workers on the morphology of the Lamellibranchs will be grateful for this paper which, without unnecessary verbosity, summarizes existing knowledge on the subject and adds materially to it. A wide range of material was examined, some eighty species from seventy-one genera and forty-six families. Excellent figures are given of conditions in many species.

The pericardial gland arises as paired groups of cells on the anterior part of the pericardium. It may extend over the auricles only or over the dorsal and ventral surfaces of the pericardium and into neighbouring parts of the mantle. In both cases it is paired and both pairs of glands may be present. The function is certainly excretory but the exact relation of this to that of the kidneys remains somewhat obscure. In only one family (Donacidæ) and five isolated genera was the gland absent. The case of Pinna is interesting. Here the gland was found in only three out of seven species. Miss White correlates this with the presence of a pre-oral gland, following Stenta who described this strange organ. It is absent in those species in which the pericardial gland is best developed. There is matter for further investigation here. The pre-oral gland opens into the infra-branchial chamber and is therefore unlikely to be concerned with the extrusion of fluid excrement, which would have to pass through the gills. On the other hand, it could produce solid excrement because this would be ejected with other waste particles by way of the inhalant opening.

The variable relations between the heart and the rectum are mentioned. Typically, the rectum traverses the heart, but in a few species it passes above or below the heart. Miss White discusses possible functional relations between the two organs, but these seem improbable and it is more likely that the different relations arise from purely morphological causes. The interesting discovery was made that the gonad may extend into the mantle in species of Arca, Spondylus and Chama, a condition hitherto recorded only in the Mytilidæ and Anomiidæ.

\section{INSULATOR GLAZES}

$\Delta \mathrm{N}$ article by E. Rosenthal in the Electrical A Review of November 27 discusses the influence of insulator glazes on porcelain, having particular reference to high-voltage insulators. Under a strong microscope the surfaces of unglazed ceramic materials show minute projecting peaks which make it evident that the quality of the surface has a great bearing on the surface resistivity. This, in turn, is largely dependent on the humidity skin which, in a moist atmosphere, forms on any surface to a thickness that increases with the surface roughness and with atmospheric humidity. With 30 per cent humidity, the surface resistance of unglazed porcelain ranges between 20 and $40 \times 10^{12} \mathrm{ohms} / \mathrm{sq}$. cm., but with 98 per cent humidity it is only about $0.001 \times 10^{12}$. This decrease in surface resistivity is smaller the smoother the surface. In a dry atmosphere glazed porcelain has approximately thesame surface resistance as unglazed porcelain, but in a humid atmosphere of, for example, 98 per cent humidity the figure becomes $0.1 \times 10^{12} \mathrm{ohms} / \mathrm{sq}$. cm. This dependence of surface resistivity on the quality of the surface and on the humidity content of the atmosphere is a characteristic not only of porcelain but also of all insulating materials.

The glaze on a porcelain insulator is composed of raw materials similar to those used for the body, but fluxes are added which cause the mixture to melt at the firing temperature of the insulator $\left(1,300-1,400^{\circ}\right.$ C.). High-temperature insulator glazes (fired at a temperature of $1,300^{\circ} \mathrm{C}$. and higher) have not only a very great influence on the surface resistivity of the insulator but also on its mechanical and physical characteristics. One of the most important factors which influence the mechanical characteristics of the glazed body is the ratio of the heat expansion of the glaze to that of the body. The most suitable glaze must be found by numerous experiments (by trial and error) for each and every body. The tensile strength, the modulus of rupture and other mechanical characteristics may be improved very considerably by the application of a glaze, the thermal coefficient of which bears the proper ratio to the thermal coefficient of the body.

The resistance to sudden temperature changes, however, may be more favourably influenced by another glaze. If the thermal expansion of the glaze does not agree with that of the body, a considerable decrease in mechanical strength may result.

Many experiments on tensile strength have been carried out in different countries and the results have been published by various authorities. In the United States it is reported that in special cases the tensile strength is increased by as much as 80 per cent by a suitable glaze, and an increase of 40 per cent is quite normal. Similar results have been obtained by Continental research workers, the tensile strength of unglazed porcelain being given as $240-320 \mathrm{kgm}$./sq. $\mathrm{cm}$. and of glazed porcelain as $300-500 \mathrm{kgm} . / \mathrm{sq}$. $\mathrm{cm}$. Tests carried out in English factory laboratories give similar results. The application of a suitable glaze not only increases the tensile strength but also the other mechanical characteristics. For example, the minimum compressive strengths of unglazed cylindrical test specimens possessing cross-sections of 160 , 80 and 20 sq. cm. are $900,1,000$ and $1,700 \mathrm{kgm} . / \mathrm{sq}$. $\mathrm{cm}$. respectively. Corresponding figures for glazed cylinders are $2,000,2,300$ and $4,300 \mathrm{kgm}$./sq. cm. These considerations apply only to porcelain glazes 